\title{
Search for ways of reconstruction of the gas transportation network to reduce gas deficits in consumers in emergencies in the gas industry
}

\author{
Sergey Vorobev $^{1 *}$, Sergey Senderov ${ }^{1}$, Alexey Edelev ${ }^{1}$ \\ ${ }^{1}$ Melentiev Energy Systems Institute, 130 Lermontov str., Irkutsk, Russia
}

\begin{abstract}
The article is devoted to the search and identification of possible invariant measures aimed at reducing gas shortages among consumers in the event of emergencies at critical facilities of the gas industry. The study was carried out on the example of the Unified Gas Supply System of Russia and is a logical development of the topic of searching and identifying critical objects of the system. The article presents a list of the most common sections of gas pipelines, the throughput of which is insufficient in the situations under consideration. As measures to reduce gas shortages among consumers in emergencies at critical facilities, the expediency of both a short-term increase in the throughput of the sections and the laying of additional sections of main gas pipelines is shown. Conclusions are drawn on the need to search for such sections of gas pipelines and to apply measures to them aimed at increasing the efficiency of the Russian gas industry in emergencies.
\end{abstract}

\section{Introduction}

Due to the significant deterioration of fixed production assets, in the absence of significant financial investments in their reconstruction, the number of major accidents in energy systems has increased in recent years. Largescale accidents in energy systems resulting from the failure of critical objects of the systems entail significant, sometimes irreparable, damage to consumers in the form of large shortages of final types of energy. According to [1], an object is critically important, partial or complete failure of which can cause significant social and economic damage to the country from the fuel and energy complex.

In the world, research is being conducted on various aspects of the analysis of the most important objects and their combinations in energy systems. Among the most relevant are the following points.

In $[2,3]$, the authors analyzed the gas transmission network to determine its most important components. The applied methodological approaches are based on topological network analysis with an emphasis on studying issues of reliability and manageability. This analysis makes it possible to quantify the reliability of the gas transmission network and determine the role of each component of the network at different time intervals. A global vulnerability analysis was carried out, taking into account possible disruptions in the operation of gas sources and main gas pipelines.

[4] presents a method for detecting and ranking critical components and component sets in technical infrastructures. The criticality of a component or set of components is defined as the vulnerability of a system to failures when a particular component or set of components fails. This problem also addresses the problem of multiple simultaneous failures with synergistic consequences that complicate the problem. The proposed method solves this problem.

In [5], the authors propose a comprehensive model for assessing the impact of the interdependence between electrical and gas systems on the reliability of power supply to consumers. Restrictions on gas supplies can affect the change in the operating mode of the electricity industry.

In [6], an analysis of possible impacts in an integrated gas and electricity network is presented. Failures of the gas supply system are considered more decisive for an integrated power supply system than failures in the power supply subsystem itself.

Studies [7, 8] are devoted to various issues of modeling energy systems as critical infrastructures. The study [8] presents a new approach to assessing the vulnerability of intercity distribution gas pipelines from accidents on gas pipelines. This approach allows the identification of vulnerable links in the pipeline network that cannot only have a significant impact on the pipeline network, but can also have a significant impact on the road network.

The presented papers consider various aspects of energy security and identify critical facilities in the power industry [9-12]. Earlier, a number of studies were carried out to identify critical objects in the gas transmission network. A list of crossings of gas pipelines in the Unified Gas Supply System of Russia has been determined, the disruption of which will lead to a relative deficit of daily gas supplies through the system

* Corresponding author: seregavorobev@isem.irk.ru 
as a whole in the amount of $5 \%$ or more [13]. Studies were carried out to search for and determine the combinations of individual sections of main gas pipelines, the simultaneous disruption of the functioning of which can lead to a significant shortage of daily gas supplies through the system (5\% or more) [14, 15]. Taking into account the previously gained experience and based on the analysis of research carried out in the world at present, in [16, 17], a methodology for the formation of lists of critical objects of energy systems from the standpoint of ensuring the operability of these systems is formulated on the example of the gas industry in Russia.

In the works reviewed, critical objects and significant objects of various levels are identified, but measures and measures aimed at reducing the significance of such objects are not presented. In this study, the authors were tasked with finding and identifying possible invariant measures aimed at reducing gas shortages among consumers in case of emergencies at critical facilities of the Unified Gas Supply System of Russia. As part of this study, the following measures have been proposed to reduce gas shortages among consumers:

- increase (up to $10 \%$ ) throughput capacity, where necessary, of the existing main gas pipelines;

- creation of additional capacities for gas transportation within the framework of the existing main gas pipelines.

\section{Mathematical formulation of the problem of finding and determining possible invariant measures aimed at reducing gas shortages among consumers in the event of an emergency at critical facilities}

In the studies carried out to determine the critical objects, a stream model was used, which is the core of the software and computing complex "Oil and Gas of Russia" [18, 19]. The use of this complex makes it possible to determine the degree of satisfaction of gas needs within the country and the provision of export supplies under various operating conditions of the gas transmission network. In addition, the Oil and Gas of Russia complex makes it possible to identify bottlenecks - sections of the gas transmission network, in some cases limiting the production capabilities of the system.

The flow distribution model in the Unified Gas Supply System used in the Oil and Gas of Russia complex is designed to assess the production capabilities of the system under conditions of various kinds of disturbances. The purpose of such studies is to minimize gas shortages at consumption nodes. The gas transportation network in the model is presented as a combination of three subsystems: gas sources, gas transmission network and its consumers.

The mathematically considered connected system is presented as a network that change in time, at the nodes of which there are enterprises for the extraction, transformation and consumption of material flows that implement material connections between enterprises. When solving the problem of assessing the state of the system after a perturbation, the criterion for optimality of the distribution of flows is the minimum energy resource deficit at the consumer with the minimum cost of its delivery.

Changing the state of the system objects leads to solving the problem of distributing flows in the system in order to maximize the supply of energy to consumers, i.e. in this case, the model is formalized as a maximum flow problem [20]. The mathematical representation of this problem is described in detail in [21].

An integrated approach to solving the assigned tasks along the entire technological chain of the system allows you to obtain an overall assessment of the production capabilities of the entire system in extreme conditions. The result of solving the problem is to determine the possibilities of satisfying consumers with network gas with the identification of the volumes of possible undersupply of gas to the consumption nodes in a particular emergency.

In the event of a gas shortage among consumers, caused by a lack of throughput capacity of the corresponding gas transmission arcs, other such arcs not affected by the violation under consideration may accept increased volumes of gas for transportation. In such a situation, the structure of the network load changes and the manifestation of a lack of capacity in certain sections of the gas transmission network is possible. Subsequent clearing of bottlenecks in the network will allow minimizing gas shortages among consumers in the context of shutdown of any facilities in the gas industry and their combinations.

The Oil and Gas of Russia complex allows the researcher, when analyzing the calculation results, to identify potential bottlenecks or network sections that limit the system's performance. Most often, these facilities can cause shortage of the required amount of gas to consumers. At the same time, without additional modeling, it is impossible to find real bottlenecks limiting the network's capabilities to supply gas to consumers in each analyzed case. A detailed mathematical statement of the bottleneck avoidance problem is described in [22].

To solve the problem of bypassing the found bottlenecks, the flow distribution model includes the possibility of increasing the gas flow along the arcs within $10 \%$ of the value of their throughput. Such a short-term increase in the throughput of a section of the main gas pipeline is possible with an increase in the operating capacity of the compressors at large main compressor stations [23]. Because of increasing the working pressure in the gas pipeline, an increase in the throughput of the main gas pipeline section is achieved within the range of up to $10 \%$. As a result (by using the technical capabilities of the gas transmission network), the problem of minimizing gas shortages among consumers is being solved.

At the same time, depending on the scale of emergencies with gas supply, not in all cases when solving the problem of bypassing bottlenecks, these gas shortages at consumers can be reduced to zero. It is 
necessary to find ways to form measures that, in the context of minimizing additional costs, in the study of each of the scenarios under consideration, would fully satisfy the consumers who potentially suffer from gas shortages when these scenarios are initially implemented. It should be recalled here that the scenarios under consideration mean shutdowns (loss of performance) of critical facilities in the gas industry or any combination of facilities in the gas industry that can lead to significant gas shortages for consumers. At this stage of research, scenarios are considered with the failure of one critical facility or one combination of two facilities in the gas industry at the same time.

The problem of minimizing gas shortages among consumers was solved by a short (at the time of the accident) increase in the capacity of gas transmission arcs with an increase in pressure at the corresponding compressor stations. By analogy with this, let us try to set the possible increments of the gas transmission arc capacity up to a certain $\Delta$ greater than the specified $10 \%$ limitation on the arc flow increment. It is clear that an increase in throughput of more than $10 \%$ of the initial one can be achieved only by creating additional capacities for gas transportation. This is both the linear part (additional lines of the gas pipeline) and additional capacities of the compressor stations. Naturally, no one will create such capacities, just in case one or another object from the list of critical objects fails. However, the task is to try to find such invariant solutions that would reduce the critical importance for the system operability of not one or two critical objects or the most important combinations of gas industry objects, but a significant number of them.

The invariant measures obtained because of the successful solution of such a problem in practice should mean the need to create additional capacities for gas transportation. It is clear that the cost of creating such capacities should be taken into account when obtaining a solution. This means that along with the constants $C i j$ and $A i j$ should be used Gij certain meaningful value of the unit cost of the gas flow in the increment of the throughput of the arc (i, j) within the framework of specially created new capacities for transporting gas along this arc. Then the task record takes the following form:

$$
\max f
$$

Under conditions:

$$
\sum_{i \in N_{j}^{+}}\left(x_{i j}+y_{i j}+g_{i j}\right)-\sum_{i \in N_{j}^{-}}\left(x_{i j}+y_{i j}+g_{i j}\right)=\left\{\begin{array}{c}
-f, j=O \\
0, j \neq O, S \\
f, j=S
\end{array}\right.
$$

$$
\begin{aligned}
& 0 \leq x_{i j} \leq d_{i j}, \text { for all }(\mathrm{i}, \mathrm{j}) \\
& 0 \leq y_{i j} \leq b_{i j}, \text { for all }(\mathrm{i}, \mathrm{j}) \\
& 0 \leq g_{i j} \leq \Delta_{i j}, \text { for all }(\mathrm{i}, \mathrm{j})
\end{aligned}
$$

$N^{+}{ }_{j}$ - subset of arcs "included" in node $\mathrm{j} ; N_{j}$ - subset of "outgoing" arcs from node $\mathrm{j} ; f$ - total network flow; $x_{i j}$ arc flow $(i, j) ; d_{i j}$ - restrictions on the flow along the arc $(i, j) ; y_{i j}$ - flow increment along the $\operatorname{arc}(i, j) ; b_{i j}-$ limitation on the flow increment along the arc $(i, j)$ within $10 \%$ of the throughput of this arc; $g_{i j}$ - flow increment along the arc $(i, j)$ within the specially created additional capacity; $\Delta i j$ - limitation on the flow increment along the arc $(i, j)$ within the specially created additional capacity.

When working with complex schemes, which are the Russian and European gas transmission networks, there may be several solutions, that is, several possible maximum flows. Then the problem of minimizing the solution cost will look like this:

$$
\sum_{(i, j)} C_{i j} x_{i j}+\sum_{(i, j)} A_{i j} y_{i j}+\sum_{(i, j)} G_{i j} g_{i j} \rightarrow \min
$$

$C_{i j}$ - unit costs for flow along the arc $(\mathrm{i}, \mathrm{j}) ; A_{i j}$ - unit costs per flow incrementally $y_{i j}$; $G_{i j}$ - unit costs per flow in increments $g_{i j}$.

\section{Search for invariant measures}

The calculation scheme used to simulate the operation of the gas transmission network takes into account all the main features of the functioning of the Unified Gas Supply System of Russia and contains:

- 378 nodes, including: 28 gas sources; 64 gas consumers (constituent entities of the Russian Federation); 24 underground gas storage facilities; 266 nodal compressor stations;

- 486 arcs representing the main gas pipelines and branches to the distribution gas networks.

Initial data, such as daily volumes of consumption, production, export and import of gas, are taken in accordance with official statistics [24-26] for 2019. In a specially conducted study [27], an analysis is presented, as a result of which 61 objects of the gas industry were classified as critical objects of the Unified Gas Supply System. Among these objects: 25 arcs between nodal compressor stations and 36 nodes, including 30 nodal compressor stations, 5 head compressor stations at the exits from large gas fields and a compressor station at one underground gas storage.

These calculations were carried out using a software package [28] that reflects in detail the functioning of the gas transmission network in Russia and allows simulating various conditions for the functioning of its facilities, including complete shutdown. The calculations were carried out using the methodology of parallel computations in the Irkutsk supercomputer center of the Siberian Branch of the Russian Academy of Sciences [29].

The situation with the alternate failure of each of the critical facilities was taken as the design scenarios. Thus, 61 calculations were carried out in order to minimize gas deficits among consumers as much as possible at the lowest cost. As a result, in order to solve this problem in the event of failure of various critical facilities, it is necessary from 35 to 85 measures, including both a short-term increase in throughput capacity and the expansion of sections of main gas pipelines. It is also worth noting that 548 such events were received for all 
61 critical facilities. Table 1 shows the most common events.

Table 1. The most frequently repeated measures to reduce gas shortages among consumers

\begin{tabular}{|c|c|c|c|c|}
\hline № & $\begin{array}{l}\text { Number of } \\
\text { repetitions } \\
\text { in } \\
\text { calculations }\end{array}$ & $\begin{array}{l}\text { Share } \\
\text { of all } \\
\text { critical } \\
\text { facilitie } \\
\mathrm{s}, \%\end{array}$ & $\begin{array}{l}\text { The volume of } \\
\text { increasing the } \\
\text { throughput of the } \\
\text { corresponding } \\
\text { arc of the design } \\
\text { graph, million } \\
\mathrm{m}^{3} / \text { day. }\end{array}$ & $\begin{array}{l}\text { The proportion } \\
\text { of the increase } \\
\text { in relation to } \\
\text { the original } \\
\text { throughput, } \%\end{array}$ \\
\hline 1 & 29 & 48 & 8,25 & 10 \\
\hline 2 & 25 & 41 & 6,61 & 10 \\
\hline 3 & 24 & 39 & 8,25 & 10 \\
\hline 4 & 23 & 38 & 8,25 & 10 \\
\hline $5^{*}$ & 23 & 38 & 74,25 & 100 \\
\hline 6 & 22 & 36 & 9 & 10 \\
\hline 7 & 22 & 36 & 8,25 & 10 \\
\hline 8 & 21 & 34 & 1 & 7 \\
\hline 9 & 20 & 33 & 6,61 & 10 \\
\hline 10 & 20 & 33 & 8,25 & 10 \\
\hline 11 & 20 & 33 & 6,61 & 10 \\
\hline $12 *$ & 20 & 33 & 82,5 & 100 \\
\hline 13 & 19 & 31 & 8,25 & 10 \\
\hline 14 & 18 & 30 & 8,25 & 10 \\
\hline $15 *$ & 18 & 30 & 74,25 & 100 \\
\hline 16 & 17 & 28 & 8,25 & 10 \\
\hline 17 & 17 & 28 & 8,25 & 10 \\
\hline 18 & 16 & 26 & 8,25 & 10 \\
\hline 19 & 16 & 26 & 1 & 7 \\
\hline 20 & 16 & 26 & 3,046 & 10 \\
\hline 21 & 16 & 26 & 8,25 & 10 \\
\hline 22 & 16 & 26 & 9 & 10 \\
\hline 23 & 16 & 26 & 8,25 & 10 \\
\hline $24 *$ & 16 & 26 & 59,49 & 72 \\
\hline 25 & 15 & 25 & 8,25 & 10 \\
\hline 26 & 15 & 25 & 1,35 & 10 \\
\hline $27 *$ & 15 & 25 & 82,5 & 100 \\
\hline
\end{tabular}

Table 1 shows that in the current configuration of the Russian gas transmission network there are 27 sections where it is advisable to expand the throughput capacity with a high degree of invariance (from 25 to $48 \%$ of the scenarios under consideration). It is advisable to add plans for the corresponding expansion of these sections to the programs for the reconstruction and development of the Unified Gas Supply System of Russia. The increase in throughput at sections 5, 12, 15, 24, 27 implies the construction of additional lines of gas trunklines. Such measures are much more expensive than a short-term increase in throughput capacity, but the frequency of their repetition in the conditions under consideration indicates their need from the standpoint of improving the fuel supply to consumers in emergencies at gas industry facilities.

It should be pointed out that even under such design conditions, 23 critical facilities remain in the system, in the event of a malfunction of which consumers remain in shortage of gas.

\section{Conclusion}

The article is devoted to the search and identification of possible invariant measures aimed at reducing gas shortages among consumers in the event of emergencies at critical facilities of the gas industry. A list of the most frequently encountered sections of main gas pipelines, the throughput capacity of which is insufficient in the situations under consideration, is presented. As measures to reduce gas shortages among consumers in emergencies at critical facilities, the expediency of both a short-term increase in the throughput of the sections and the laying of additional sections of main gas pipelines is shown. It is noted that under the scenarios under consideration, a number of critical facilities remain in the system, in the event of a malfunction of which consumers remain in shortage of gas.

Conclusions are drawn about the need to search for such sections of gas pipelines and apply measures to them aimed at increasing the operability of the Russian gas industry in emergencies.

This work has been supported by the grants the Russian Science Foundation, RSF 20-79-00242.

\section{References}

1. S.M. Senderov, V.I. Rabchuk, A.V. Edelev. Features of the formation of the list of critical objects of the gas transmission network of Russia, taking into account the requirements of energy security and possible measures to minimize the negative consequences of emergencies at such facilities // Izvestia of the Russian Academy of Sciences. Energetica, 2016, No. 1, pp. 70-78.

2. Han F. \& Zio E. \& Kopustinskas V. \& Praks P. Quantifying the importance of elements of a gas transmission network from topological, reliability and controllability perspectives, considering capacity constraints. In book: Risk, Reliability and Safety: Innovating Theory and Practice, 2016, pp. 2565-2571. DOI 10.1201/9781315374987-389,

3. Su H., Zio E., Zhang J. Li X. A systematic framework of vulnerability analysis of a natural gas pipeline network. Reliability Engineering \& System Safety, Volume 175, July 2018, Pages 79-91 https://doi.org/10.1016/j.ress.2018.03.006

4. Jonsson H., Johansson J., Johansson H. Identifying critical components in technical infrastructure networks. Proceedings of the Institution of Mechanical Engineers, Part O: Journal of Risk and Reliability. 2008. Vol. 222. No. 2. P. 235-243. https://doi.org/10.1243\% 2F1748006XJRR138

5. Li T., Eremia M., Shahidehpour M., Interdependency of natural gas network and power system security, IEEE Transactions on Power Sys-tems, 2008, vol. 23, 1817-1824. https://doi.org/10.1109/ TPWRS.2008.2004739

6. Dokic S.B., Rajakovic N.Lj. Security Modelling of Integrated Gas and Electrical Power Systems by Analyzing Critical Situations and Potentials for Performance Optimization. Energy (2018), doi: 10.1016/j.energy. 2018.04.165

7. Thompson, J. R., Frezza, D., Necioglu, B., Cohen, M. L., Hoffman, K., Rosfjord, K. (2019). "Interdependent Critical Infrastructure Model (ICIM): An agent-based model of power and water 
infrastructure". International Journal of Critical Infrastructure Protection Volume 24, p. 144-165.

8. Kai, L., Ming, W., Weihua, Z., Jinshan, W., Xiaoyong, Y. (2018). "Vulnerability analysis of an urban gas pipeline network considering pipeline-road dependency". International Journal of Critical Infrastructure Protection Volume 23, p. 79-89.

9. Iakubovskii D., Komendantova N., Rovenskaya E., Krupenev D., Boyarkin D. Impacts of earthquakes on energy security in the Eurasian economic union: Resilience of the electricity transmission networks in Russia, Kazakhstan, and Kyrgyzstan // Geosciences (Switzerland). Vol.9. №1. ID: 54. 2019. DOI: 10.3390/geosciences9010054

10. Krupenev D. Determination of Critically Objects of Electric Power Systems from the Position of Energy Security // E3S Web of Conferences. Vol.58. ID: 03009. 2018. DOI: $10.1051 / \mathrm{e} 3$ sconf $/ 20185803009$

11. Krupenev D., Boyarkin D., Iakubovskii D. Improvement in the computational efficiency of a technique for assessing the reliability of electric power systems based on the Monte Carlo method // Reliability Engineering and System Safety. Vol.204. ID: 107171. 2020. DOI: 10.1016/j.ress.2020.107171

12. Krupenev D. Assessment of Power System Adequacy with Renewable Energy Sources and Energy Storage Systems // E3S Web of Conferences. Vol.58. ID: 01012. 2018. DOI: 10.1051/e3sconf/20185801012

13. Senderov S., Edelev A. Formation of a List of Critical Facilities in the Gas Transportation System of Russia in Terms of Energy Security // 2017. Energy. doi:10.1016/J.ENERGY.2017.11.063.

14. Vorobev S., Edelev A. Analysis of the importance of critical objects of the gas industry with the method of determining critical elements in networks of technical infrastructures // Management of Large-Scale System Development (MLSD), 2017 Tenth International Conference. $\quad$ IEEE, $2017 . \quad$ DOI 10.1109/MLSD.2017.8109707.

15. Vorobev S., Edelev A., Smirnova E. Search of critically important objects of the gas industry with the method of determining critical elements in networks of technical infrastructures // Methodological Problems in Reliability Study of Large Energy Systems (RSES 2017). E3S Web Conf. Volume 25, 2017. DOI 10.1051/e3sconf/ 20172501004.

16. Senderov S., Edelev A. Formation of a list of critical facilities in the gas transportation system of Russia in terms of energy security. Energy, 2019, doi:10.1016/j.energy.2017.11.063.

17. S.M. Senderov, S.V. Vorobev, Approaches to the identification of critical facilities and critical combinations of facilities in the gas industry in terms of its operability. Reliability Engineering \& System Safety,
Volume 203, 107046, 2020, doi: 10.1016/j.ress.2020.107046.

18. Edelev A.V., Enikeeva S.M., Senderov S.M. Information support in the study of the functioning of large pipeline systems // Computational technologies, 1999, Volume 4, No. 5, pp. 30 - 35.

19. Khramov A.V., Enikeeva S.M., Khrustaleva N.M. et al. Software and information support for solving problems of survivability of the Unified Gas Supply System of the USSR // in Methods and Models for Studying the Survivability of Energy Systems, Novosibirsk: Nauka, Sib. dep, 1990, p. 86-91.

20. Ford L.R., Fulkerson D.R. Flows in Networks / Princeton University Press, Princeton, New Jersey, 1962, $276 \mathrm{p}$.

21. Vorobev S.V., Edelev A.V. Features of mathematical modeling in the distribution of surplus gas in the Unified Gas Supply System of Russia / Scientific Bulletin of NSTU vol. 62, No. 1, 2016. - p. 181-194.

22. Vorobev S.V., Edelev A.V. Methodology for determining bottlenecks in the operation of large pipeline systems // Software products and systems, 2014, No. 3, pp. 174 - 177.

23. Extraction, preparation and transportation of natural gas and condensate. Reference manual in 2 volumes. Volume II / Ed. Yu.P. Korotaev, R.D. Margulov. - M .: Nedra, $1984.288 \mathrm{p}$.

24. Exports of the Russian Federation of the most important goods in 2012 - 2020 (according to the Federal Customs Service

Russia)http://customs.ru/index.php?option = $\quad$ com newsfts \& view $=$ category\&id $=52 \&$ Item $\mathrm{id}=1978 \&$ limitstart $=60$.

25. InfoTEK Monthly oil and gas magazine. No. 1, 2020, p. 154.

26. Ministry of Energy of the Russian Federation. Statistics. http://minenergo.gov.ru/activity/statistic.

27. Senderov S.M., Rabchuk V.I., Vorobev S.V. Formation of a list of critical objects of the gas industry from the standpoint of the country's energy security / Materials of a collection of reports Methodological issues of researching the reliability of large energy systems 90th meeting "Reliability of developing energy systems". July 1-7, 2018, Irkutsk.

28. Feoktistov A., Gorsky S., Sidorov I., Kostromin R., Edelev A., Massel L. Orlando Tools: Energy Research Application Development through Convergence of Grid and Cloud Computing / Communications in Computer and Information Science. 2019. Vol. 965. P. 289-300. 29. Irkutsk Supercomputer Center SB RAS. URL: http://hpc.icc.ru 